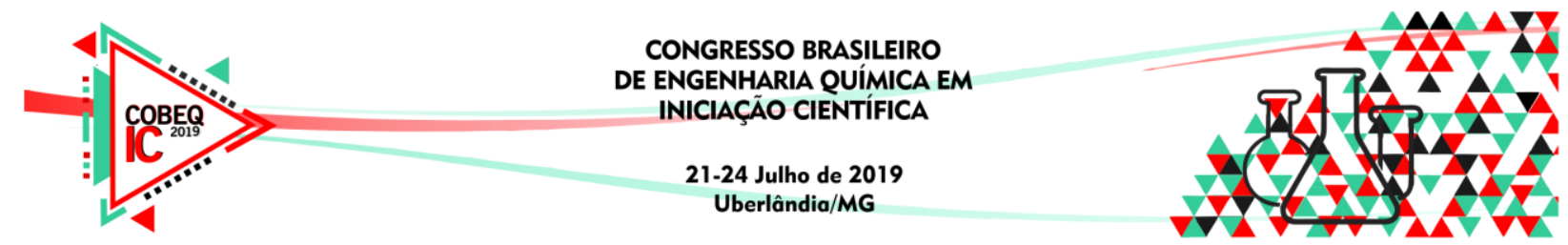

\title{
DETERMINAÇÃO DE MACRONUTRIENTES SECUNDÁRIOS E MICRONUTRIENTES EM PLANTAS DE MILHO ADUBADAS COM FERTILIZANTE ORGANOMINERAL
}

\author{
B. D. FELIZARDO ${ }^{1}$, E. S. ARAÚJO2 ${ }^{2}$ I. V. S. JUNIOR ${ }^{1}$, \\ A. A. ROCHA ${ }^{2}$, D. V. B. CAMPOS ${ }^{3}$ \\ ${ }^{1}$ Universidade de Vassouras, Curso de Engenharia Química, Vassouras, Brasil, RJ \\ ${ }^{2}$ Embrapa Agrobiologia, Seropédica, Brasil, RJ \\ ${ }^{3}$ Embrapa Solos, Rio de Janeiro, RJ \\ E-mail para contato: biianca_domingos@hotmail.com
}

\begin{abstract}
RESUMO - A determinação dos teores de macro e micronutrientes através das análises químicas é importante para avaliar a ciclagem de nutrientes nos sistemas produtivos. O objetivo deste trabalho foi avaliar o efeito da aplicação de um fertilizante organomineral fosfatado no acúmulo de macro e micronutrientes na parte aérea de milho, cultivado em solo de baixa fertilidade localizado em Seropédica - RJ. Foi plantada a cultivar híbrido BR3025, em delineamento experimental de blocos ao acaso, com quatro repetições, em que cada parcela correspondeu a uma área de $5 \times 5 \mathrm{~m}$. Os seis tratamentos foram: Fosfato Natural Reativo; Superfosfato simples; fertilizante Organomineral nas proporções de 50, 100 e $150 \%$ da dose recomendada; e uma Testemunha (sem adubação fosfatada). Como fonte de $\mathrm{N}$, foi aplicada torta de mamona em todos os tratamentos. Na colheita do milho, a parte aérea foi separada em grãos e biomassa, e ambas frações foram pesadas, moídas e levadas para análise química elementar em equipamento ICP OES no polo INOVASOLOS na Embrapa Solos. Não houve diferença significativa na produtividade de milho entre os tratamentos. Só houve efeito da adubação para os parâmetros teores de cobre e zinco na biomassa e acúmulo de cobre na parte aérea do milho.
\end{abstract}

\section{INTRODUÇÃO}

O rendimento de milho no estado do Rio de Janeiro está abaixo da produtividade média nacional, principalmente pela baixa fertilidade natural dos solos cariocas (Freire et al., 2013). Por isso, o uso de fertilizantes é recomendável para o fornecimento dos nutrientes, e os fertilizantes organominerais se apresentam como uma alternativa, pois contribuem para uma destinação correta de resíduos orgânicos. Os fertilizantes organominerais são obtidos a partir da mistura de fertilizantes orgânicos e minerais, exigindo menores custos, e instalações, comparados à produção de fertilizantes minerais, sendo uma alternativa viável para pequenos e médios produtores. Além de apresentar algumas vantagens, como por exemplo, sua matéria prima vem de resíduos de outros sistemas de produção, diminuindo os impactos ambientais (Benites et al., 2010).

A quantificação dos nutrientes em sistemas de produção é importante para se avaliar o balanço nutricional das plantas, indicando as entradas via adubação, e as exportações via colheita, indicando se o plantio está aumentando, diminuindo ou conservando os nutrientes em quantidades adequadas para uma boa fertilidade do solo. 


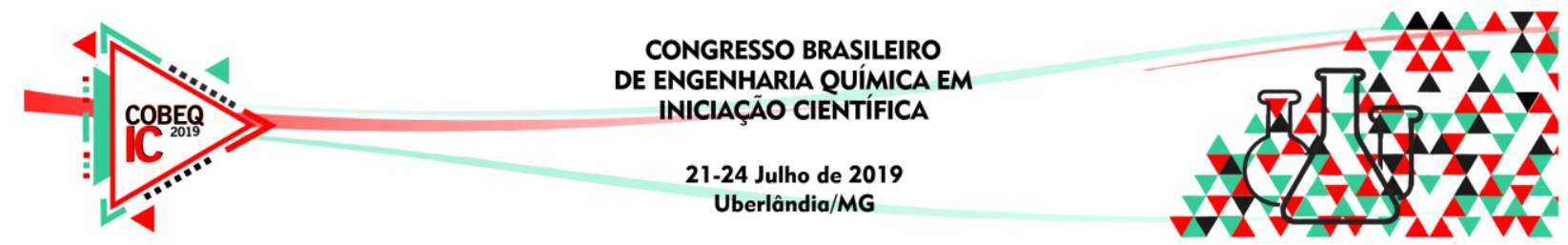

Diante do exposto, este presente trabalho teve como objetivo avaliar o efeito da aplicação de um fertilizante organomineral fosfatado, produzido a partir da compostagem de dejetos suínos, no acúmulo de macronutrientes secundários e micronutrientes na parte aérea de milho cultivado em solo arenoso de baixa fertilidade natural.

\section{MATERIAL E MÉTODOS}

\subsection{Plantio do Experimento}

O fertilizante organomineral foi produzido pela Embrapa Solos. O experimento de campo foi conduzido no Campo Experimental da Embrapa Agrobiologia - Terraço, localizado em Seropédica - Rio de Janeiro - Brasil, situado a $22^{\circ} 45^{\prime} 28^{\prime \prime}$ de latitude sul e a $43^{\circ} 41^{\prime} 05^{\prime \prime}$ de longitude oeste e a uma altitude média de $33 \mathrm{~m}$. Apresentando clima Aw com verão úmido e inverno seco, segundo a classificação de Köppen, que é classificação global dos tipos climática mais utilizada em geografia, climatologia e ecologia. $\mathrm{O}$ solo onde foi instalado o experimento é classificado como Argissolo Vermelho Amarelo.

Por ocasião do plantio do milho, foi realizada adubação e calagem de acordo com a análise de solo (Freire et al., 2013). O delineamento experimental foi o de blocos ao acaso, com quatro repetições. As parcelas corresponderam a uma área de 5 x $5 \mathrm{~m}$. Foram estabelecidos seis tratamentos para adubação fosfatada: 1) Fosfato Natural; 2) Superfosfato simples; 3) Organomineral com 50\% da dose recomendada para a cultura do milho; 4) Organomineral com 100\% da dose; 5) Organomineral com 150\% da dose; 6) Testemunha (sem adubação fosfatada). Em todas as parcelas foi realizada a semeadura do milho (Zea mays), cultivar híbrido BR3025. Para a adubação nitrogenada, optou-se pela adição de torta de mamona, adequada aos sistemas orgânicos de produção.

\subsection{Coleta de amostras}

No momento da colheita, a parte aérea do milho foi separada em grãos e biomassa, sendo coletadas amostras que foram secas em estufa de circulação de ar a $70^{\circ} \mathrm{C}$ até que as amostras apresentassem peso constante. Sendo depois pesadas, para determinação de massa seca de grãos e biomassa, e posteriormente moídas, em moinho tipo willey com peneira de 1 mm de diâmetro (20-40 mesh), para a realização das análises químicas em tecido vegetal (Carmo et al., 2000).

\subsection{Análises Químicas}

Para as análises químicas, foi seguida a metodologia descrita pelo Manual de Métodos de Análises de Tecidos Vegetais (CARMO et al., 2000) dos laboratórios da Embrapa Solos. A abertura das amostras ocorreu em bloco digestor utilizando solução nitroperclórica. A quantificação dos elementos $\mathrm{Ca}, \mathrm{Mg}, \mathrm{Cu}, \mathrm{Fe}, \mathrm{Mn}$ e $\mathrm{Zn}$ foi por Espectrometria de Emissão Atômica com fonte de Plasma (ICP - OES), modelo Perkin Elmer optima 3000 e software ICP winlad.

Para a análise estatística dos resultados, foi utilizado o programa SISVAR 5.6 (Ferreira, 2014). Os resultados foram analisados estatisticamente por meio de análise de 


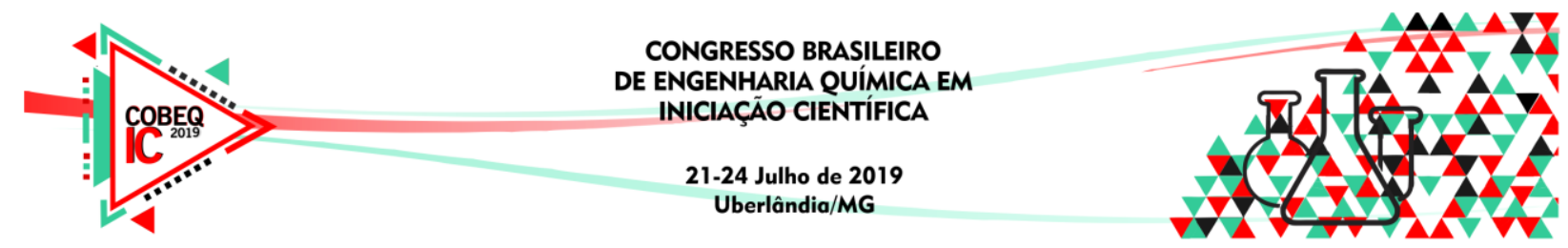

variância (teste $\mathrm{F}$; $\operatorname{Pr}<0,05)$ e, ocorreu efeito significativo, os tratamentos foram comparados pelo teste de Tukey $(\operatorname{Pr}<0,05)$.

\section{RESULTADOS E DISCUSSÃO}

Pela análise química dos grãos e da biomassa foi possível estimar a exportação destes nutrientes pelas culturas em relação às diferentes formas de manejo da adubação do solo.

Pôde-se observar que não houve diferença entre os diferentes tratamentos em relação aos teores de $\mathrm{Ca}, \mathrm{Mg}$, Fe e $\mathrm{Zn}$. Em relação ao $\mathrm{Zn}$, foi observado um teor mais elevado no tratamento com adubação de fertilizante organomineral de $150 \%$. Já para o cobre, foi observado um aumento de teor na biomassa de milho adubada com superfosfato simples (Tabela 1).

Tabela 1 - Teores de nutrientes na biomassa de milho adubado com fertilizantes fosfatados em Seropédica (RJ).

\begin{tabular}{|c|c|c|c|c|c|c|}
\hline Tratamento & $\mathrm{Ca}$ & $\mathrm{Mg}$ & $\mathrm{Fe}$ & $\mathrm{Mn}$ & $\mathrm{Zn}$ & $\mathrm{Cu}$ \\
\hline & $\mathrm{g} \mathrm{kg}^{-1}$ & $\mathrm{~g} \mathrm{~kg}^{-1}$ & $\mathrm{~g} \mathrm{~kg}^{-1}$ & $\mathrm{~g} \mathrm{~kg}^{-1}$ & $\mathrm{mg} \mathrm{kg}^{-1}$ & $\mathrm{mg} \mathrm{kg}^{-1}$ \\
\hline Fostato Natural Reativo & 1,65 & 1,95 & 0,155 & 0,053 & $24,5 a b$ & $3,4 \mathrm{~b}$ \\
\hline Superfosfato Simples & 1,78 & 1,9 & 0,180 & 0,060 & $20,1 a b$ & $5,4 \quad a$ \\
\hline Organomineral $50 \%$ & 1,55 & 1,7 & 0,118 & 0,038 & $17,3 \quad b$ & $3,4 \mathrm{~b}$ \\
\hline Organomineral $100 \%$ & 1,78 & 2,05 & 0,153 & 0,055 & $23,0 a b$ & $3,6 b$ \\
\hline Organomineral $150 \%$ & 1,87 & 2,05 & 0,148 & 0,055 & 29,8 a & $3,9 \mathrm{~b}$ \\
\hline Testemunha & 1,55 & 1,98 & 0,145 & 0,053 & $25,5 a b$ & $3,5 b$ \\
\hline $\mathrm{CV}(\%)$ & 22,4 & 16,5 & 23,1 & 25,7 & 21,9 & 21 \\
\hline
\end{tabular}

Em relação aos teores dos nutrientes $\mathrm{Ca}, \mathrm{Mg}, \mathrm{Fe}, \mathrm{Mn}, \mathrm{Zn}$ e $\mathrm{Cu}$ nos grãos de milho, pôde-se observar que não houve diferença entre os tratamentos, isto é, não houve efeito da adubação nos teores destes elementos (Tabela 2).

Tabela 2 - Teores de nutrientes nos grãos de milho adubado com fertilizantes fosfatados em Seropédica $(\mathrm{RJ})$.

\begin{tabular}{|c|c|c|c|c|c|c|}
\hline Tratamento & $\mathrm{Ca}$ & $\mathrm{Mg}$ & $\mathrm{Fe}$ & $\mathrm{Mn}$ & $\mathrm{Zn}$ & $\mathrm{Cu}$ \\
\hline Fostato Natural Reativo & $\mathrm{g} \mathrm{kg}^{-1}$ & $\mathrm{~g} \mathrm{~kg}^{-1}$ & $\mathrm{~g} \mathrm{~kg}^{-1}$ & $\mathrm{~g} \mathrm{~kg}^{-1}$ & $\mathrm{mg} \mathrm{kg}^{-1}$ & $\mathrm{mg} \mathrm{kg}^{-1}$ \\
\hline Superfosfato Simples & 0,07 & 1,2 & 27,5 & 7,3 & 28,7 & 2,7 \\
\hline Organomineral 50\% & 0,08 & 1,2 & 28,2 & 7,2 & 25,3 & 2,7 \\
\hline Organomineral 100\% & 0,07 & 1,2 & 28,1 & 8,4 & 31,1 & 2,9 \\
\hline Organomineral 150\% & 0,07 & 1,2 & 27,9 & 7,5 & 27,1 & 2,5 \\
\hline Testemunha & 0,06 & 1 & 26,1 & 6,6 & 25,6 & 2,6 \\
\hline Cv (\%) & 33,3 & 19,6 & 16,4 & 19,6 & 18,7 & 14,1 \\
\hline
\end{tabular}

CV \% - Percentual do coeficiente de variância. 


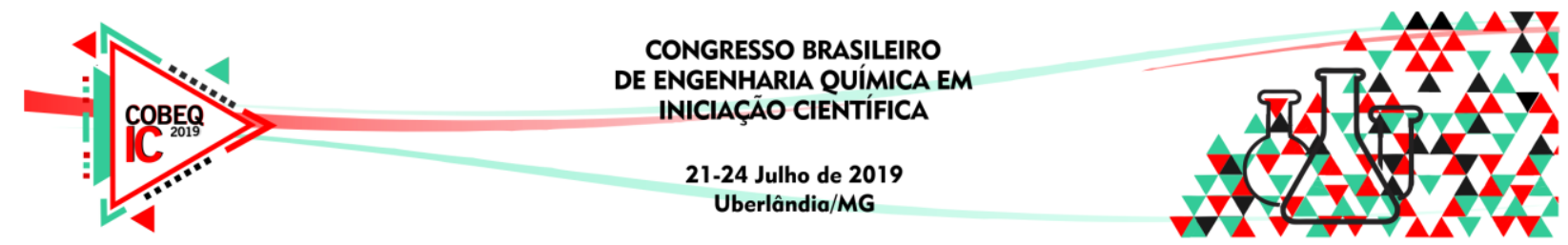

$\mathrm{O}$ acúmulo dos macronutrientes $\mathrm{Ca}$ e $\mathrm{Mg}$, e dos micronutrientes $\mathrm{Fe}, \mathrm{Mn}$ e $\mathrm{Zn}$ não diferiram estatisticamente (Tabela 3). Somente foi observada diferença estatística no acúmulo de cobre na parte aérea do milho adubado com superfosfato simples.

Esses dados concordam com o trabalho de Rocha et al (2014), que observaram que não houve diferença entre os tratamentos com adubação da testemunha sem aplicação de fertilizante. Provavelmente a adubação com a torta de mamona para fornecimento de $\mathrm{N}$ também adicionou os demais nutrientes, fazendo com que a produtividade da testemunha fosse satisfatória.

Tabela 3 - Acúmulo de nutrientes na parte aérea (biomassa + grão) de milho adubado com fertilizantes fosfatados em Seropédica (RJ).

\begin{tabular}{|c|c|c|c|c|c|c|}
\hline Tratamento & $\mathrm{Ca}$ & $\mathrm{Mg}$ & $\mathrm{Fe}$ & $\mathrm{Mn}$ & $\mathrm{Zn}$ & $\mathrm{Cu}$ \\
\hline & $\mathrm{kg} \mathrm{ha}^{-1}$ & $\mathrm{~kg} \mathrm{ha}^{-1}$ & $\mathrm{~kg} \mathrm{ha}^{-1}$ & $\mathrm{~kg} \mathrm{ha}^{-1}$ & $\mathrm{~g} \mathrm{ha}^{-1}$ & $\mathrm{~g} \mathrm{ha}^{-1}$ \\
\hline Fostato Natural Reativo & 13,5 & 21,6 & 1,3 & 0,45 & 336,6 & $40,3 \quad b$ \\
\hline Superfosfato Simples & 15,1 & 21,8 & 1,6 & 0,54 & 288,8 & $56 a$ \\
\hline Organomineral $50 \%$ & 11,7 & 19,7 & 1 & 0,32 & 291,2 & $39,5 \quad b$ \\
\hline Organomineral $100 \%$ & 13,2 & 21,5 & 1,2 & 0,43 & 310,8 & $39,9 \quad b$ \\
\hline Organomineral $150 \%$ & 14 & 21,1 & 1,2 & 0,44 & 346,8 & $41,4 \mathrm{ab}$ \\
\hline Testemunha & 10,6 & 18,4 & 1,1 & 0,4 & 304,8 & $36,3 \quad b$ \\
\hline $\mathrm{Cv}(\%)$ & 29 & 22,3 & 25 & 28,2 & 18,9 & 16,4 \\
\hline
\end{tabular}

*Médias seguidas de letras minúsculas indicam diferença significativa por tukey a $5 \%$.

\section{CONCLUSÃO}

Não houve diferença significativa na produtividade de milho entre os tratamentos. Só houve efeito da adubação para os parâmetros teores de cobre e zinco na biomassa e acúmulo de cobre na parte aérea do milho. Possibilidades de estudos posteriores.

\section{REFERÊNCIAS}

BENITES, V. de M.; CORREA, J. C.; MENEZES, J. F. S.; POLIDORO, J. C. Produção de fertilizante organomineral granulado a partir de dejetos de suínos e aves no Brasil. REUNIÃO BRASILEIRA DE FERTILIDADE DO SOLO E NUTRIÇÃO DE PLANTAS, 29.; REUNIÃO BRASILEIRA SOBRE MICORRIZAS, 13.; SIMPÓSIO BRASILEIRO DE MICROBIOLOGIA DO SOLO, 11.; REUNIÃO BRASILEIRA DE BIOLOGIA DO SOLO, 8., 2010, Guarapari. Fontes de nutrientes e produção agrícola: modelando o futuro: anais. Viçosa: SBCS, 2010. 5 p.

CARMO, C. A. F. S.; ARAÚJO, W. S. A.; BERNARDI, A. C. C.; SALDANHA, M. F. C. Métodos de análise de tecidos vegetais utilizados na Embrapa solos. Rio de Janeiro, Embrapa Solos, 2000. 


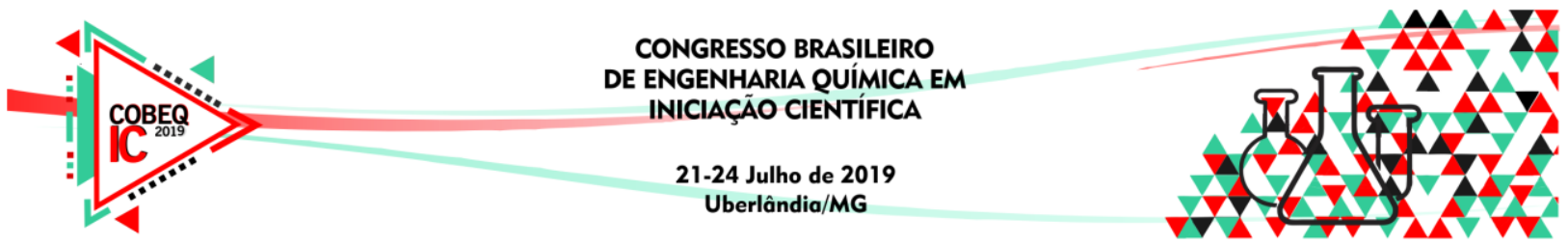

FERREIRA, D.F. Sisvar: a Guide for its Bootstrap procedures in multiple comparisons. Ciência e Agrotecnologia 2014, 38, 109.

FREIRE, L.F.; BALIEIRO,F.C; ZONTA, E.; ANJOS, L.H.C.; PEREIRA, M.G.; LIMA, E.; GUERRA, J.G.M.; FERREIRA, M.B.C.; LEAL, M.A.A.; CAMPOS, D.V.B.; POLIDORO, J.C. Manual de Calagem e Adubação do Estado do Rio de Janeiro. 430 p. Ed: Universidade Rural e Embrapa. 2013.

ROCHA, A. A.; SOUZA, F. H. ; SILVA, B. F. ; CAMPOS, D. V. B. ; POLIDORO, J. C. ; ARAUJO, E. S. . Efeito de fertilizante organomineral obtido a partir de resíduos de suínos sobre a produtividade de milho verde. In: Semana Científica Johanna Döbereiner, 2014, Seropédica - RJ. Anais da Semana Científica Johanna Döbereiner. Seropédica: Embrapa, 2014. v. XIV., 2014. 